\title{
Article \\ Living-Cell Diffracted X-ray Tracking Analysis Confirmed Internal Salt Bridge Is Critical for Ligand-Induced Twisting Motion of Serotonin Receptors
}

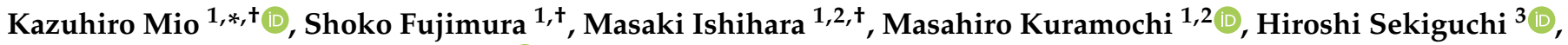 \\ Tai Kubo ${ }^{1,2}$ and Yuji C. Sasaki ${ }^{1,2,3, * \text { (D) }}$ \\ 1 AIST-UTokyo Advanced Operando-Measurement Technology Open Innovation \\ Laboratory (OPERANDO-OIL), National Institute of Advanced Industrial Science and Technology (AIST), \\ 6-2-3 Kashiwanoha, Chiba 277-0882, Japan; shoko-san@aist.go.jp (S.F.); masaki.ishihara30@gmail.com (M.I.); \\ masahiro-kuramochi@edu.k.u-tokyo.ac.jp (M.K.); tai.kubo@edu.k.u-tokyo.ac.jp (T.K.) \\ 2 Graduate School of Frontier Sciences, The University of Tokyo, 5-1-5 Kashiwanoha, Chiba 277-8561, Japan \\ 3 Center for Synchrotron Radiation Research, Japan Synchrotron Radiation Research Institute, 1-1-1 Kouto, \\ Sayo-cho, Hyogo 679-5198, Japan; sekiguchi@spring8.or.jp \\ * Correspondence: kazu.mio@aist.go.jp (K.M.); ycsasaki@edu.k.u-tokyo.ac.jp (Y.C.S.) \\ + These authors contributed equally to this work.
}

\section{check for}

updates

Citation: Mio, K.; Fujimura, S.; Ishihara, M.; Kuramochi, M.;

Sekiguchi, H.; Kubo, T.; Sasaki, Y.C.

Living-Cell Diffracted X-ray Tracking

Analysis Confirmed Internal Salt

Bridge Is Critical for Ligand-Induced

Twisting Motion of Serotonin

Receptors. Int. J. Mol. Sci. 2021, 22,

5285. https://doi.org/10.3390/

ijms22105285

Academic Editor: Alexander Shpakov

Received: 11 April 2021

Accepted: 14 May 2021

Published: 17 May 2021

Publisher's Note: MDPI stays neutral with regard to jurisdictional claims in published maps and institutional affiliations.

Copyright: (c) 2021 by the authors. Licensee MDPI, Basel, Switzerland. This article is an open access article distributed under the terms and conditions of the Creative Commons Attribution (CC BY) license (https:// creativecommons.org/licenses/by/ $4.0 /)$.
Abstract: Serotonin receptors play important roles in neuronal excitation, emotion, platelet aggregation, and vasoconstriction. The serotonin receptor subtype $2 \mathrm{~A}\left(5-\mathrm{HT}_{2 \mathrm{~A}} \mathrm{R}\right)$ is a Gq-coupled GPCR, which activate phospholipase $\mathrm{C}$. Although the structures and functions of $5-\mathrm{HT}_{2 \mathrm{~A}}$ Rs have been well studied, little has been known about their real-time dynamics. In this study, we analyzed the intramolecular motion of the $5-\mathrm{HT}_{2 \mathrm{~A}} \mathrm{R}$ in living cells using the diffracted X-ray tracking (DXT) technique. The DXT is a very precise single-molecular analytical technique, which tracks diffraction spots from the gold nanocrystals labeled on the protein surface. Trajectory analysis provides insight into protein dynamics. The 5- $\mathrm{HT}_{2 \mathrm{~A}}$ Rs were transiently expressed in HEK 293 cells, and the gold nanocrystals were attached to the N-terminal introduced FLAG-tag via anti-FLAG antibodies. The motions were recorded with a frame rate of $100 \mu$ s per frame. A lifetime filtering technique demonstrated that the unliganded receptors contain high mobility population with clockwise twisting. This rotation was, however, abolished by either a full agonist $\alpha$-methylserotonin or an inverse agonist ketanserin. Mutation analysis revealed that the "ionic lock" between the DRY motif in the third transmembrane segment and a negatively charged residue of the sixth transmembrane segment is essential for the torsional motion at the $\mathrm{N}$-terminus of the receptor.

Keywords: GPCR; 5- $\mathrm{HT}_{2 \mathrm{~A}}$ receptor; intramolecular dynamics; live cell; X-ray diffraction analysis

\section{Introduction}

G-protein-coupled receptors (GPCRs) play important roles in a wide variety of physiological functions, such as signal sensing, immune system processes, and neurotransmission. Metabotropic serotonin receptor subtype $2 \mathrm{~A}\left(5-\mathrm{HT}_{2 \mathrm{~A}} \mathrm{R}\right)$ is widely distributed in the central nervous system, and are involved in neuronal excitation, learning, and emotion. The 5$\mathrm{HT}_{2 \mathrm{~A}} \mathrm{Rs}$ are also important for platelet aggregation, vasoconstriction, and vascular smooth muscle proliferation [1-3]. The activation of Gq-coupled 5- $\mathrm{HT}_{2 \mathrm{~A}}$ Rs results in activation of phospholipase $C$, which consequently hydrolyzes phosphatidylinositol 4,5-bisphosphate into secondary messengers' inositol 1,4,5-trisphosphate and diacylglycerol [4].

The structures of $5-\mathrm{HT}_{2 \mathrm{~A}} \mathrm{R}$ have been solved by crystallography and cryoelectron microscopy $[5,6]$. However, it is technically challenging to detect the intramolecular motions of membrane proteins directly, because signal transduction comprises a multistep movement with various directions and speed ranging from a microsecond ( $\mu$ s) to a 
millisecond (ms) time scale. They are beyond the temporal and spatial resolution of most imaging-based techniques.

To elucidate the fast and microscale dynamics of $5-\mathrm{HT}_{2 \mathrm{~A}} \mathrm{Rs}$ in live cells, we used the diffracted X-ray tracking (DXT) technique in this analysis. The DXT analyzes the motion of target proteins through statistical analysis of diffraction spots from the gold nanocrystals labeled on the protein surface [7-10]. Using a synchrotron radiation source and a high-speed detector, conformational dynamics, as well as functional intermediates, can be detected in a time-resolved manner from $\mu$ s to ms scale with sub-angstrom spatial information. We have also recently developed a diffracted X-ray blinking (DXB) technique, which uses low-dose monochromatic X-rays and analyzes continuation of signals by calculating the autocorrelation function of each pixel from the recorded data $[11,12]$.

In our previous study using DXT and DXB techniques, we were able to detect various 5- $\mathrm{HT}_{2 \mathrm{~A}} \mathrm{Rs}$ motion components according to the recording frame rate [13]. In that, the ligandinduced conformational shift from multiple structures to active or inactive conformation at different time scales was observed. However, the detail in the twisting movement of each transmembrane segment was not clarified yet. Using the lifetime filtering technique [10], we analyzed here the torsional movement of the $\mathrm{N}$-terminal domain of $5-\mathrm{HT}_{2 \mathrm{~A}} \mathrm{R}$.

\section{Results}

We analyzed the ligand induced intramolecular motion of $5-\mathrm{HT}_{2 \mathrm{~A}} \mathrm{Rs}$ in living cells using the DXT technique (Figure 1a,b). The motion was recorded at a frame rate of $100 \mu \mathrm{s}$ per frame, and the resulting diffraction spots were analyzed in two rotational axes of tilt $(\theta)$ and twist $(\mathrm{X})$ angles. We analyzed 319 through 1291 trajectory points for each condition.
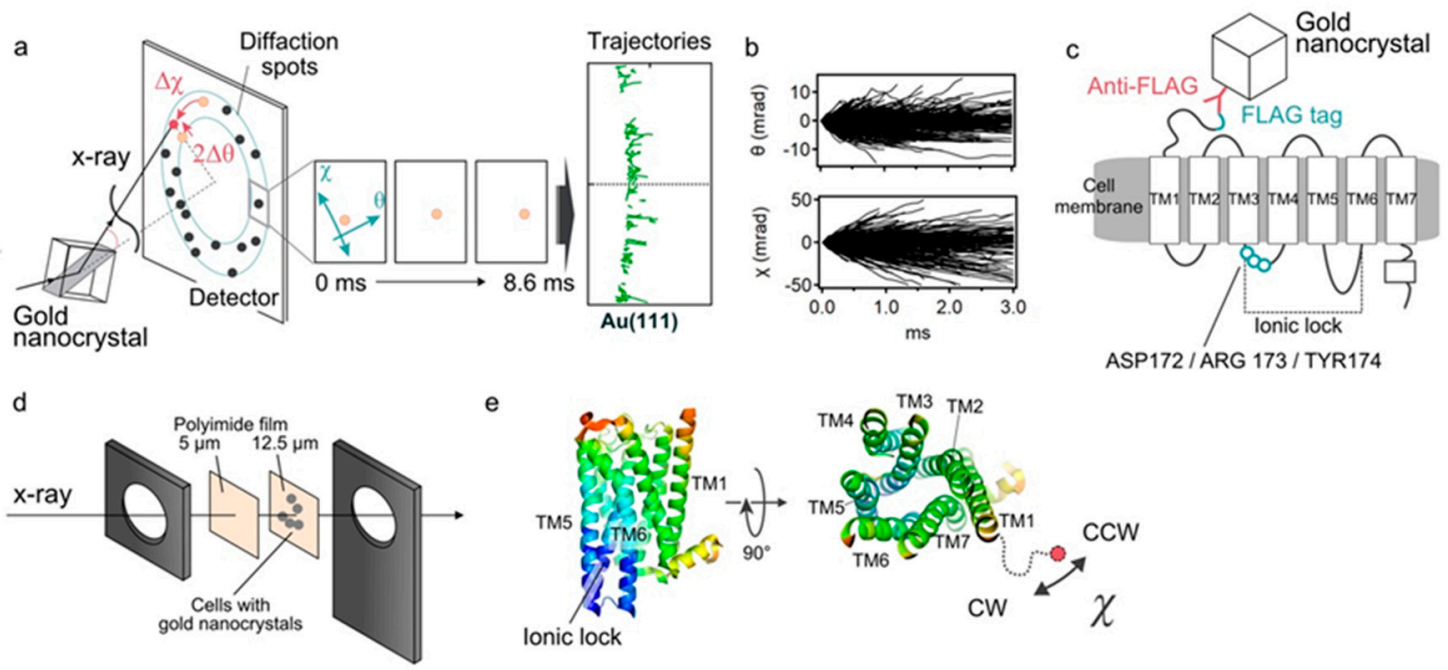

Figure 1. Diffracted X-ray tracking (DXT) measurements. (a) Schematic of the DXT measurement. Gold nanocrystals were labeled at specific positions of the target proteins, and their motion was determined by the analysis of the diffraction spots. Pink-beam X-rays elicited trackable diffraction spots from the gold nanocrystals. The central three panels show movement of diffraction spots. The right panel shows piled data of $\mathrm{Au}$ (111) spots, representing trajectories. (b) An angular displacement along $\theta$ and $\chi$ axes over time $(3.0 \mathrm{~ms})$. The trajectories were projected and analyzed on the $\chi-\theta$ coordinates, separately. The 1291 traces obtained from the ligand-free condition are presented. (c) Labeling of $5-\mathrm{HT}_{2 \mathrm{~A}} \mathrm{Rs}$ with gold nanocrystals. The FLAG-tag introduced at the N-terminus was labeled by FLAG antibody-gold nanocrystals conjugates. After washing out the unbound gold nanocrystals, the motion of 5- $\mathrm{HT}_{2 \mathrm{~A}}$ Rs was measured. (d) Preparation of the sample holder. FLAG-tagged $5-\mathrm{HT}_{2 \mathrm{~A}}$ Rs was transiently expressed in the HEK293 cells, and they were cultured on the surface of 12.5 - $\mu$ m-thick polyimide films. After labeling the receptors with FLAG antibody-gold nanocrystal conjugates, the cells were covered with 5- $\mu$ m-thick polyimide films with $20 \mu \mathrm{L}$ chamber buffer. They were sandwiched by stainless steel frames. (e) Spatial arrangement of the transmembrane helices of $5-\mathrm{HT}_{2 \mathrm{~A}}$ Rs viewed from side and top (reconstituted from the PDB: 6A93). The 5-HT $2 \mathrm{~A}$ comprises intrinsically disordered $\mathrm{N}$-terminal domain of approximately 75 amino acids. Gold nanocrystals were attached to the N-terminal end of the TM1 via the anti-FLAG antibody. Regarding the twisting motion, negative value $(\Delta x<0)$ represent clockwise $(\mathrm{CW})$ rotation, while positive value $(\Delta x>0)$ represent counter-clockwise $(\mathrm{CCW})$ rotation. 
The FLAG sequence (DYKDDDDK) was introduced genetically at the N-terminal end of the 5-HT ${ }_{2 A} \mathrm{R}$. The HEK293 cells expressing $5-\mathrm{HT}_{2 \mathrm{~A}}$ Rs were cultured on the surface of polyimide films, and its N-terminus was labeled with anti-FLAG antibody conjugated with gold nanocrystals (Figure 1c,d). Expression and function of the expressed receptor constructs were confirmed by the immunocytochemistry, live-cell immunofluorescence assay and calcium influx assay (Figure S1). We also confirmed using the trypan blue dye exclusion method that the cell viability under all experimental conditions was as high as $97 \%$ (data not shown). The cells were cultured at confluency so that every recording spot provides effective signals as well as reducing background from the nonspecifically bound golds. As for the twisting motion, the negative value $(\Delta x<0)$ represents the clockwise rotation $(\mathrm{CW})$, while the positive value $(\Delta x>0)$ represents the counter-clockwise rotation (CCW) (Figure 1e).

\subsection{DXT Analysis of $5-H T_{2 A} R$}

In order to apply DXT to living cells, radiation damage should be minimized. In the previous study, we found that narrowing the bandwidth of X-ray eliminated cell damage [13]. So we used X-rays with 0.02 energy bandwidth, $15 \mathrm{keV}$ peak energy and $10^{13}$ photon/s flux for the living-cell DXT, instead of the $15.8 \mathrm{keV}$ white X-ray that is commonly used for single molecular DXT.

We first analyzed the time-averaged mean square displacement (MSD) curves using the diffraction tracks obtained (Figure 2a and Table S1) [14]. As reported in the previous study, the slope in the $\theta$ direction was suppressed by the full agonist $\alpha$-methylserotonin $(\alpha \mathrm{MS})$ and the $\alpha \mathrm{MS}$ with inverse agonist ketanserin ( $\alpha \mathrm{MS} /$ ket) (Figure 2a). This was considered due to the shift of conformational equilibrium from multiple structures to active or inactive conformation [13,15].

This time the MSD curves in the $\chi$ directions were analyzed (Figure 2a, lower panel). Slopes of $\alpha \mathrm{MS}$ and $\alpha \mathrm{MS} / \mathrm{ket}$ in $\chi$ direction were also decreased from that of unliganded $5-\mathrm{HT}_{2 \mathrm{~A}} \mathrm{R}$. Although most conditions represent restricted curves $(\alpha<1)$, the unliganded and $\alpha \mathrm{MS}$ were superdiffused (Table S1, $\alpha=1.67$ and 1.74, respectively). For simple Brownian diffusion, MSD plots represent linear slope of $4 \mathrm{D}$, where $\mathrm{D}$ is the diffusion coefficient. These superdiffusion plots, however, are indicative of directed diffusion.

To understand the reason of superdiffusion curve of the unliganded receptor, we analyzed the motion of individual receptor. The displacement distribution graphs represent the travel distance from the original point in $1 \mathrm{~ms}$ (100 $\mu \mathrm{s} \times 10$ frames) and $1.6 \mathrm{~ms}(100 \mu \mathrm{s} \times$ 16 frames) (Figure 2b). The MSD curve shows the average motion, while the displacement distribution represents the motion of the constituent components.

In addition to the main population peaking at $\Delta x=0$, another population representing the torsion movement of $\mathrm{CW}(\Delta \mathrm{x}<0)$ was observed (Figure $2 \mathrm{~b}$, red arrows). This high mobility group was also recognized in the two-axis distribution graphs of $\theta$ and $\chi$ coordinates (dotted circles in the Figure 2b, lower panels), which comprise 33\% of the total probability density at $\Delta \mathrm{t}=1 \mathrm{~ms}$ (Figure S2). Subpopulation peaks were $-10.1 \mathrm{mrad}$ at $\Delta \mathrm{t}=1 \mathrm{~ms}$, and $-19.1 \mathrm{mrad}$ at $\Delta \mathrm{t}=1.6 \mathrm{~ms}$.

The displacement distribution of $10 \mu \mathrm{M} \alpha \mathrm{MS}$ was mostly fitted by single Gaussian curves and the fast moving subpopulation was not observed (Figure 2c). GPCR proteins in the native condition have a conformational balance among inactive, active, and a number of intermediate states. Elimination of high mobility group by $\alpha \mathrm{MS}$ may represent the shift of conformational equilibrium from multiple structures to active conformation [15].

Ketanserin is a competitive inverse agonist to $5-\mathrm{HT}_{2 \mathrm{~A}} \mathrm{R}$ with $\mathrm{Ki}=2-3 \mathrm{nM}$ (The PDSP Ki database; https://pdsp.unc.edu/databases/kidb.php (accessed on 1 May 2021). We then analyzed the $5-\mathrm{HT}_{2 \mathrm{~A}} \mathrm{R}$ motion with $\alpha \mathrm{MS} /$ ket. The variance $\left(\sigma^{2}\right)$ of the Gaussian curves fitted for $\alpha \mathrm{MS} / \operatorname{ket}(1.3$ at $\Delta \mathrm{t}=1 \mathrm{~ms}$ ) was much lower than those of other conditions (2.6 and 2.7 for unliganded and $\alpha \mathrm{MS}$, respectively), suggesting the 5- $\mathrm{HT}_{2 \mathrm{~A}} \mathrm{R}$ treated with $\alpha \mathrm{MS} /$ ket appeared to have a reduced fluctuation (Figure $2 \mathrm{~d}$ and Table S2). 

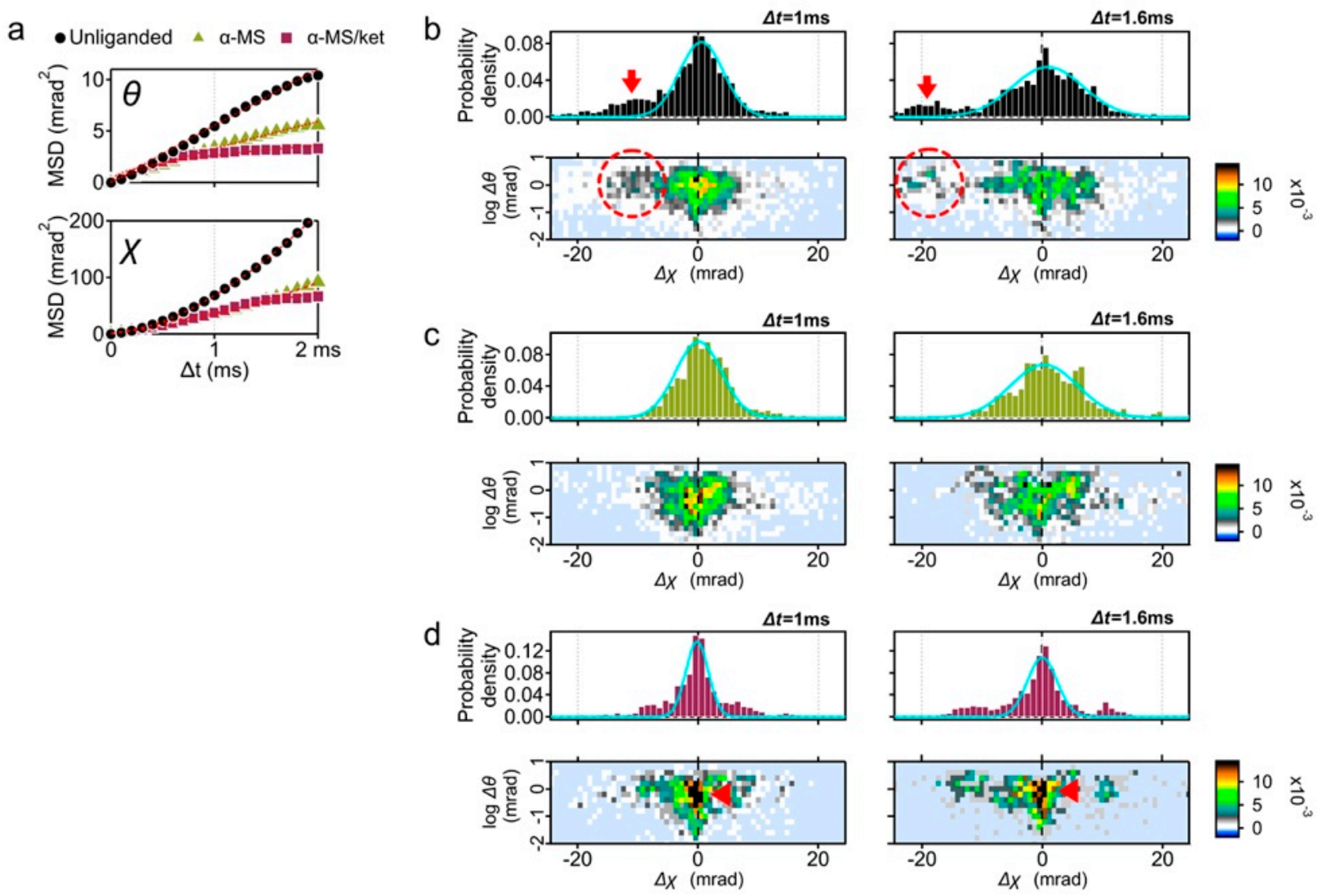

Figure 2. DXT analysis of the wild-type 5- $\mathrm{HT}_{2 \mathrm{~A}} \mathrm{R}$. (a) Mean square displacement (MSD) curves of 5-HT $\mathrm{A}_{2} \mathrm{R}$ motion for the $\theta$ and $\chi$ axis; unliganded control (black circles), in the presence of $10 \mu \mathrm{M} \alpha$-methylserotonin ( $\alpha \mathrm{MS}$, green triangles), and $10 \mu \mathrm{M} \alpha \mathrm{MS}$ with $100 \mu \mathrm{M}$ ketanserin ( $\alpha \mathrm{MS} /$ ket, red squares). (b) Distribution of the absolute angular displacement of the wild-type $5-\mathrm{HT}_{2 \mathrm{~A}} \mathrm{R}$ over an interval time $\mathrm{t}$ (upper left panel, $\Delta \mathrm{t}=1 \mathrm{~ms}$, and upper right panel, $\Delta \mathrm{t}=1.6 \mathrm{~ms}$ ). Main population in the histograms are fitted by the Gaussian curves. Two-axis distribution maps of $\theta$ (vertical axis with logarithmic scale) and $\chi$ (horizontal axis) are presented at the lower row. Fast moving component toward CW direction was indicated by arrows (upper panels) and dotted circles (lower panels). The same analysis was applied to the DXT of (c) $\alpha \mathrm{MS}$, and (d) $\alpha \mathrm{MS} /$ ket. Slow moving population in $\alpha \mathrm{MS} /$ ket were shown by red arrows.

The intramolecular motion of the wild-type $5-\mathrm{HT}_{2 \mathrm{~A}} \mathrm{R}$ was further analyzed over time from the two-axis map (Figure 3 ). The unliganded $5-\mathrm{HT}_{2 \mathrm{~A}} \mathrm{R}$ clearly shows the highly mobile group with the $\mathrm{CW}$ rotation $(\Delta x<0)$, which mostly have the higher $\theta$ value (Figure 3a, indicated by dotted circles). The mean value of the Gaussian curves adapted to the highly mobile group was $-10.1 \mathrm{mrad}$ (Figure S2). The high mobility group was not present in both $\alpha \mathrm{MS}$ and $\alpha \mathrm{MS} / \mathrm{ket}$ (Figure $3 \mathrm{~b}, \mathrm{c}$ ). In response to the smaller variance $\left(\sigma^{2}\right)$ in the Gaussian curve, the population with low mobility remained in $\alpha \mathrm{MS} /$ ket even at $\Delta \mathrm{t}=1.6 \mathrm{~ms}$ (Figure 3c, dark filled pixels indicated by a red arrow). 
a

\section{$\Delta t=$ \\ $0.1 \mathrm{~ms}$}

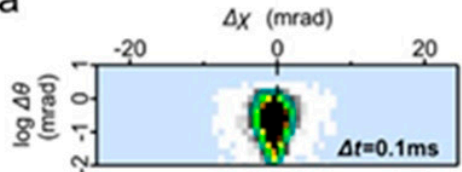

$0.4 \mathrm{~ms}$

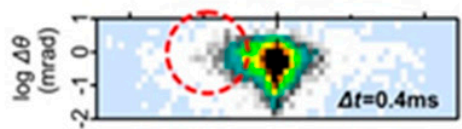

$1.0 \mathrm{~ms}$

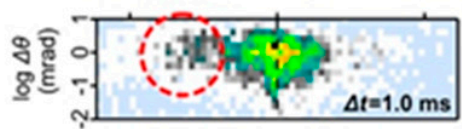

$1.6 \mathrm{~ms}$

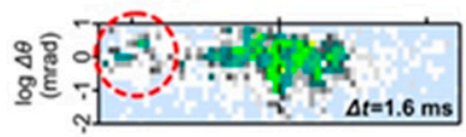

Unliganded b
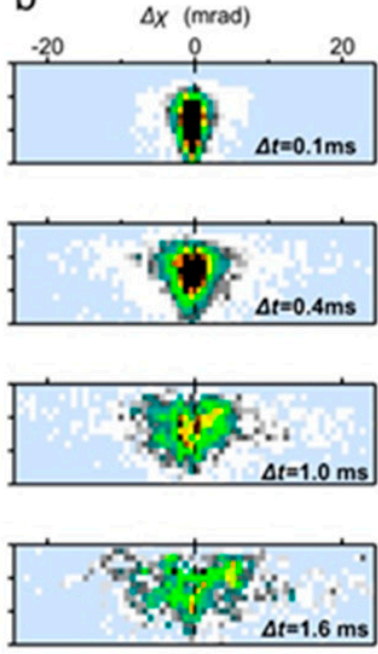

$\underline{\mathrm{aMS}}$
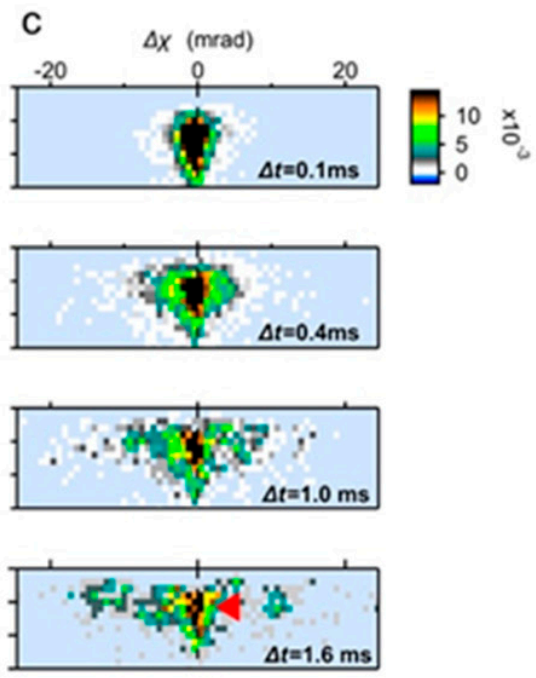

$\underline{\mathrm{aMS} / \mathrm{Ket}}$

Figure 3. Time course of the wild-type 5- $\mathrm{HT}_{2 \mathrm{~A}} \mathrm{R}$ motion in the two-axis map. (a) Distribution transition of the wild type $5-\mathrm{HT}_{2 \mathrm{~A}} \mathrm{R}$ motion in the absence of ligand. Subpopulation representing twisting motion toward $\mathrm{CW}(\Delta x<0)$ are circled. (b) Distribution transition of the receptor in the presence of $\alpha$ MS. The fast moving component was not seen. (c) Distribution transition of the receptor in the presence of $\alpha \mathrm{MS} /$ ket. Low mobility group remained even in the $\Delta \mathrm{t}=1.6 \mathrm{~ms}$ (dark filled pixels, indicated by an red arrow).

\subsection{Motion Comparison by Two-Axis Subtraction Maps}

To understand the ligand induced dynamics of $5-\mathrm{HT}_{2 \mathrm{~A}} \mathrm{R}$, subtraction analysis was performed. In the subtraction map between the unliganded and $\alpha \mathrm{MS}$, the population in fast movement was dominated in unliganded (Figure 4a, red pixels). Most of them belonged to high $\theta$ scores, and the torsion direction was $\mathrm{CW}(\Delta x<0)$. On the contrary, the subtracted $\alpha \mathrm{MS}$ was mainly found at $\Delta \chi \sim 0 \mathrm{mrad}$ with low $\theta$ scores (Figure $4 \mathrm{a}$, blue pixels). The mobility of $5-\mathrm{HT}_{2 \mathrm{~A}} \mathrm{R}$ was further reduced by $\alpha \mathrm{MS} / \mathrm{ket}$ and its large population remains at $\Delta \chi \sim 0 \mathrm{mrad}$ (Figure $4 \mathrm{~b}$ ). This is consistent with the presence of $\alpha \mathrm{MS} /$ ket low mobility populations (Figure $2 \mathrm{~d}$ ).

The high mobility population of unliganded $5-\mathrm{HT}_{2 \mathrm{~A}} \mathrm{R}$ was also highlighted by the time series subtraction graphs between the unliganded and $\alpha \mathrm{MS}$ (Figure $4 \mathrm{c}$, red arrows).

\subsection{Motion Analysis of the DRY/AAY Mutant}

The displacement distribution for the DRY/AAY mutant was also analyzed. The DRY / AAY mutation disrupts an "ionic lock" between the third transmembrane segment and the second intracellular loop. Because the ionic lock stabilizes the structure in an inactive form, its disruption often undergoes constitutive activity [16,17]. 


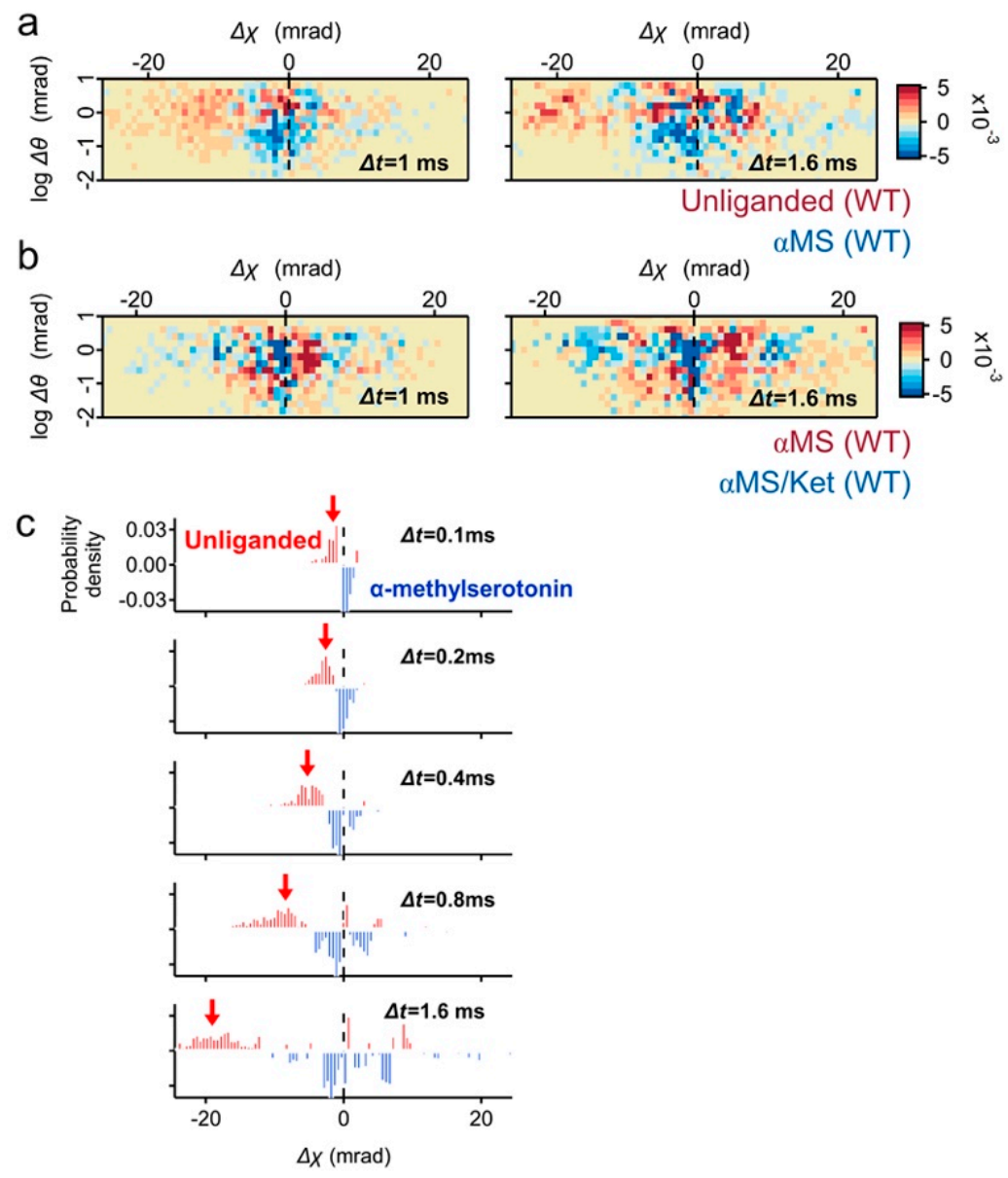

Figure 4. Subtraction analysis of the wild-type $5-\mathrm{HT}_{2 \mathrm{~A}} \mathrm{R}$ motion in the two-axis map. (a) Two-axis subtraction maps of the wild type $5-\mathrm{HT}_{2 \mathrm{~A}} \mathrm{R}$ between unliganded control (red pixels) and $\alpha \mathrm{MS}$ (blue pixels). Population representing $\mathrm{CW}$ movement $(\Delta \chi<0)$ are dominated in the unliganded, while major population of $\alpha \mathrm{MS}$ remain at $\Delta \mathrm{\chi} \sim 0$. (b) Two-axis subtraction maps of wild type 5-HT2A $\mathrm{R}$ between $\alpha \mathrm{MS}$ (red) and $\alpha \mathrm{MS} /$ ket (blue). The large population of $\alpha \mathrm{MS} /$ ket remains at $\Delta \chi \sim 0$. (c) Time course of subtraction map in $\chi$ distribution between unliganded (blue) and $\alpha \mathrm{MS}$ (red). The CW twisting population was clearly shown in unliganded (red arrows).

The displacement distribution of the DRY/AAY mutant fitted with a single peak shows the distribution is not symmetrical to the y-axis; shoulder angle at the minus $\Delta \chi$ (left side of the shoulder) was steeper than the plus $\Delta \chi$ (right side of the shoulder) (Figure $5 \mathrm{a}$, upper panels). The motion of DRY/AAY mutant proteins are confined and are considered to have fluctuated asymmetrically along the $\chi$ axis. In three Gaussian curve fitting, the main peak position was shifted from $\chi=0.2 \mathrm{mrad}$ in the WT (Figure S2d-peak2, 60\% area ratio at $\Delta \mathrm{t}=1 \mathrm{~ms}$ ) to $\chi=-0.9 \mathrm{mrad}$ in the DRY $/$ AAY (Figure S3d-peak1, $83 \%$ area ratio at $\Delta \mathrm{t}=1 \mathrm{~ms}$ ), suggesting clear bias of DRY / AAY mutant to the CW direction. This probably represents a conformational shift from structural equilibrium of multiple states of the WT to a stabilized active conformation in DRY/AAY due to the disruption of ionic lock. The fast-moving population was also not found in both $\alpha \mathrm{MS}$ and $\alpha \mathrm{MS} /$ ket (Figure $5 \mathrm{~b}, \mathrm{c})$. The two-axis subtraction maps and the time course of subtraction in the $\chi$ distribution have not shown a clear difference between the unliganded and $\alpha \mathrm{MS}$ in the DRY / AAY mutant (Figure 5d,e). 
a

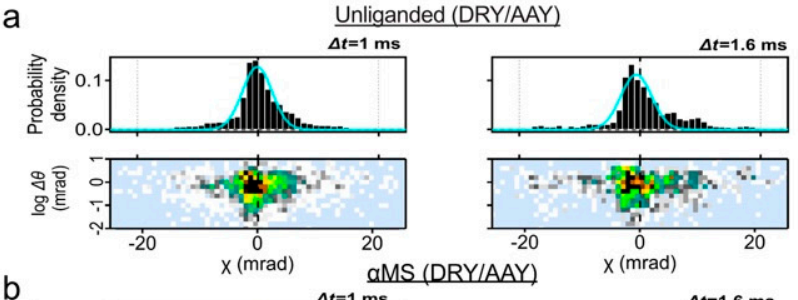

b

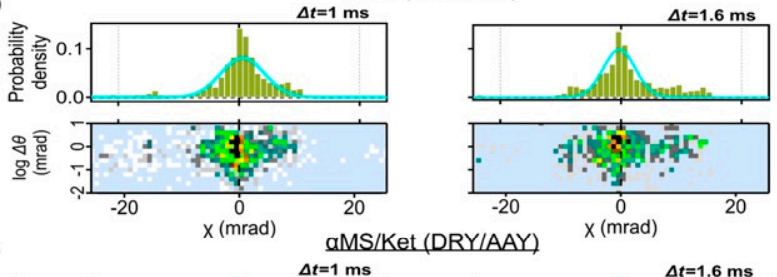

C

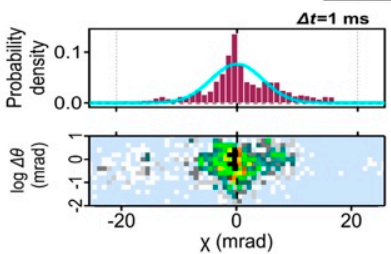

d

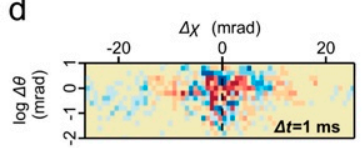

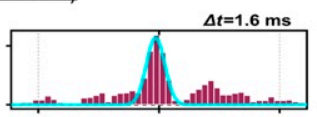
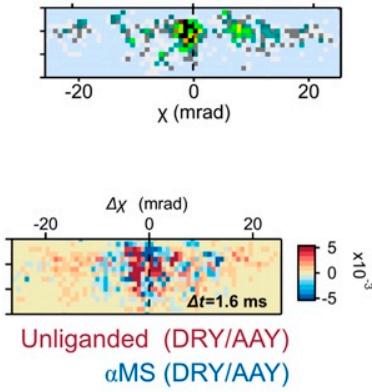

e
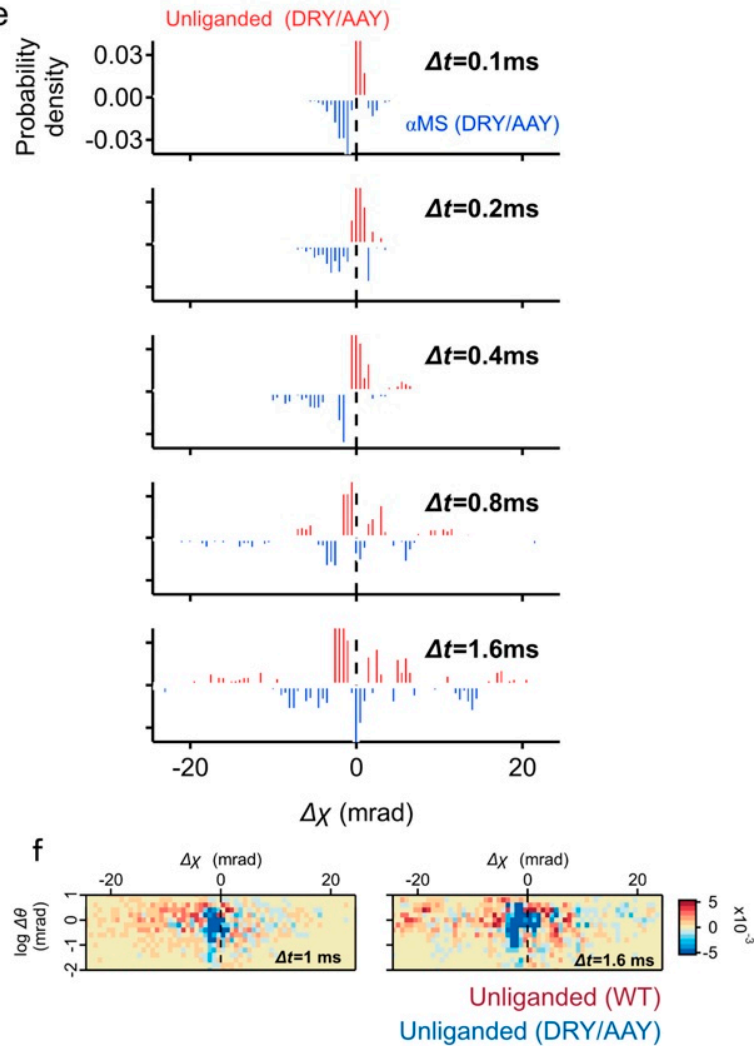

Figure 5. DXT analysis of the DRY/AAY mutant. (a-c) Distributions of the absolute angular displacement over an interval time $\mathrm{t}(\Delta \mathrm{t}=1$, and $1.6 \mathrm{~ms})$ for unliganded, $\alpha \mathrm{MS}$ and $\alpha \mathrm{MS} /$ Ket. Main populations in the histograms are fitted by the Gaussian curves. Two-axis distribution maps of $\theta$ (vertical axis with logarithmic scale) and $\chi$ (horizontal axis) are presented at the lower rows. (d) Two-axis subtraction maps between the unliganded wild-type 5- $\mathrm{HT}_{2 \mathrm{~A}} \mathrm{R}$ (red) and unliganded DRY / AAY mutant (blue). Population representing CW movement $(\Delta x<0)$ are dominated in wild-type 5- $\mathrm{HT}_{2 \mathrm{~A}} \mathrm{R}$, while low mobility group of DRY / AAY mutant remains at $\Delta \chi \sim 0$. (e) Two-axis subtraction maps of the DRY/AAY mutant between unliganded (blue) and $\alpha$ MS (red). Population of $\alpha$ MS was slightly dispersed. (f) Time course of subtraction map in $\chi$ distribution of the DRY/AAY mutant between unliganded (blue) and $\alpha \mathrm{MS}$ (red).

The two-axis subtraction map between the wild-type (unliganded) and the DRY / AAY (unliganded) again confirmed that the fast-moving population with $\mathrm{CW}$ movement $(\Delta x<0)$ is dominated in the wild-type (Figure $5 \mathrm{f}$ ). A large population of DRY / AAY remains at $\Delta \chi \sim 0$.

\section{Discussion}

In this study, the dynamics of $5-\mathrm{HT}_{2 \mathrm{~A}} \mathrm{R}$ were analyzed in living cells using DXT techniques. The bandwidth of X-rays was reduced to eliminate cell damage, compared to the X-rays used in a single DXT molecule. We have successfully detected the torsional movement of $5-\mathrm{HT}_{2 \mathrm{~A}} \mathrm{R}$ in living cells.

From this analysis, a clockwise torsional motion of $10.1 \mathrm{mrad}\left(0.58^{\circ}\right)$ was elucidated at $\Delta t=1 \mathrm{~ms}$ at the $\mathrm{N}$-terminal end of the unliganded receptor. While DXT is a very sensitive measurement method, the resulting value seemed to be slightly larger than the previous results for the TRPV1 channel (averaged motion of $0.1 \mathrm{mrad}$ at $\Delta t=1 \mathrm{~ms}$ ) [10] and the estimation from the structural analysis [6].

In this experiment, the N-terminal end was labelled with a gold nanocrystal. The movement of the N-terminus can include the parallel transition on the plane of transmembrane segment 1 and the spatial arrangement caused by the torsion of the axis.

The N-terminal region of Type A GPCRs has numerous functions in ligand recognition, surface expression and signaling [18]. The N-terminal region of serotonin 2B receptor has 
a negative modulation function, and its R6G;E42G mutations increase agonist binding, cell proliferation and slow its desensitization kinetics [19]. Structural analysis of 5-HT ${ }_{2 \mathrm{~A}} \mathrm{R}$ showed that conformational rearrangements generated agonistic binding selectivity. The slow binding kinetics of lysergic acid diethylamide (LSD) to $5-\mathrm{HT}_{2 \mathrm{~A}} \mathrm{R}$ are driven by a "lid" formed at the binding pocket by extracellular loop 2, which stabilizes the ligandreceptor complex [20]. Indeed, the molecular docking studies support the ligand-induced conformational rearrangement of the serotonin receptors [21,22].

The N-terminal structures of GPCRs type A are not well understood as they are considered intrinsically disordered. Indeed, most structural data do not include information about the $\mathrm{N}$-terminus. The findings of this study show that the movement of $\mathrm{N}$-terminus varies considerably depending on the presence or absence of the ligand, suggesting that the $5-\mathrm{HT}_{2 \mathrm{~A}} \mathrm{R} \mathrm{N}$-terminal can also have a certain effect on bound ligand stabilization. To separate the motions of the $\mathrm{N}$-terminal domain and of the transmembrane 1, comparative DXT experiments using $\mathrm{N}$-terminally truncated and/or other mutants that disturb the interaction of the N-terminus with the TMs core will be necessary. An overall picture of $5-\mathrm{HT}_{2 \mathrm{~A}} \mathrm{R}$ motion is expected through detailed time-resolved measurements of each functional domain.

The "ionic lock" between the E/DRY motif of the third transmembrane segment and a negatively charged residue of the sixth transmembrane segment plays an important role in the regulation of the GPCR function [16]. Because the ionic lock stabilizes the structure in an inactive form, its disruption frequently leads to a constitutive active receptor [16,17]. In this study, the mutant DRY / AAY protein which disturbs the ionic lock lost the clockwise torsion motion observed in the wild type. This is consistent with our previous report that the loss of ionic lock lost the fluctuation of the receptor analyzed in the $\theta$ direction [13].

In the native state, most GPCRs are considered to have multiple structures under the conformational balance between active and inactive conformations. The rapid-motion group observed in the unliganded receptor histograms can be the population representing the displacement of these two stages. This DXT study confirmed the critical role of the intramolecular ionic lock in switching between active and inactive forms. A recent study using fluorine nuclear magnetic resonance spectroscopy demonstrated adenosine $\mathrm{A}_{2 \mathrm{~A}}$ receptors facilitate at least two distinct active states and three inactive states [23]. The number of active conformations introduced by the breakage of ionic lock in DRY / AAY still remains unclear.

In this DXT analysis, we mainly focused on the intramolecular dynamics of 5- $\mathrm{HT}_{2 \mathrm{~A}} \mathrm{R}$. However, to understand the total regulation of the receptor, intermolecular association with the effector proteins such as G-proteins and arrestins, and higher ordered movement including receptor dimerization and cell integration should be considered [24]. Binding of $G$ protein was shown to stabilize an activation intermediate in adenosine $A_{2 A}$ receptors, and Gs $\alpha \beta \gamma$ shifts the receptor equilibrium to a predominantly active ensemble [23]. Furthermore, molecular dynamics simulations have shown that the dynamics of an adenosine A2a receptor vary significantly according to the lipid environment [25].

Motion dynamics are considered to occur in nanosecond to millisecond order. Our DXT measurement adopted recording speed of $100 \mu \mathrm{s} /$ frame, and nanosecond ordered fast motion could not be captured in this study. Extending analysis including synchronizing timescale with MD simulations may be helpful. Combined analysis with other single molecular analysis techniques, as well as further establish of the DXT studies using reconstituted GPCR-signaling complexes from the purified proteins, will be needed.

\section{Materials and Methods}

\subsection{DNA Construction and Transfection}

A full-length human 5- $\mathrm{HT}_{2 \mathrm{~A}} \mathrm{R}$ was subcloned into pcDNA3.1, and a FLAG sequence (DYKDDDDK) was introduced at the N-terminus using the inverse PCR system (Toyobo biotech, Osaka, Japan). Mutant constructs were made by site-directed mutagenesis using the QuikChange mutagenesis kit (Agilent Technologies, Santa Clara, CA, USA). The se- 
quences of all constructs were verified by DNA sequencing. The FreeStyle HEK 293-F cells (Thermo Fisher, Waltham, MA, USA) were grown under suspension culture in FreeStyle 293 Expression Medium (Thermo Fisher) at $37^{\circ} \mathrm{C}$ under $5 \% \mathrm{CO}_{2}$. Cells were transfected using a mixture at a ratio of one $\mu \mathrm{g}$ plasmid DNA: polyethyleneimine MAX (Polysciences, Warrington, PA, USA) =1:3 (weight) into $1 \mathrm{~mL}$ of cells at a density of $2 \times 10^{6}$ cells $/ \mathrm{mL}$. The next day after transfection, the cells were inoculated on the surface of the $12.5 \mu \mathrm{m}$ thick polyimide films (Kapton, Du Pont-Toray) that were treated with $0.001 \%$ poly L-lysine (Peptide institute, Osaka, Japan) at a density of $1 \times 10^{6} \mathrm{cells} / \mathrm{cm}^{2}$ and further cultured for $12 \mathrm{~h}$. The viability of cells was examined by trypan blue dye exclusion.

\subsection{DXT Measurements}

Gold nanocrystals were fabricated by epitaxial growth on a $\mathrm{KCl}(100)$ substrate under $10^{-4} \mathrm{~Pa}$ vacuum condition. The gold nanocrystal was modified with the anti-FLAG M2 monoclonal antibody (Sigma-Aldrich: F1804, St. Louis, MO, USA) through thiol-Au chemistry. The gold nanocrystals (20-60 nm diameter) were conjugated with $100 \mu \mathrm{g}$ FLAG antibody in $1 \mathrm{~mL}$ PBS ( $\mathrm{pH}$ 8.0) under vigorous vortexing. The mixture was further dispersed with ultrasonic sonication for $30 \mathrm{~min}$ on ice. Unbound antibody was removed by centrifugation at $\times 1000 \mathrm{rpm}$ for $10 \mathrm{~min}$ twice. The sedimented conjugates were again dispersed in the $1 \mathrm{~mL}$ PBS (pH 7.4) and an aliquot of gold nanocrystal solution (50 $\mu \mathrm{L})$ was reacted with the receptor expressing cell surface $(7 \times 7 \mathrm{~mm}$ area) at room temperature. After $30 \mathrm{~min}$, unbound gold conjugates were washed away twice with PBS. They were covered with $5-\mu \mathrm{m}$-thick polyimide films with $20 \mu \mathrm{L}$ chamber buffer, and sandwiched by stainless steel frames and screw-clamped.

DXT measurements were conducted using the SPring-8 BL40XU beamline. The beam size was adjusted to $50 \mu \mathrm{m}$ in diameter by inserting a pinhole aperture upstream of the sample, and time-resolved diffraction images from the gold nanocrystals were recorded by an X-ray image intensifier (V7739P, Hamamatsu photonics, Hamamatsu city, Japan) and a CMOS camera (Phantom V2511, Vision Research, Wayne, NJ, USA). For each sample, diffractions at 36 positions $(6 \times 6)$ within $1 \mathrm{~mm}^{2}(1 \mathrm{~mm} \times 1 \mathrm{~mm})$ were recorded. The distance between the sample and the detector was set to $50 \mathrm{~mm}$. X-rays with an energy bandwidth of 0.02 ( $15 \mathrm{keV}$ in peak energy and photon flux of $10^{13}$ photon/s) were used for the living-cell DXT to minimize damage to the cells (usual DXT uses X-rays with an energy bandwidth of 0.1 and $15.8 \mathrm{keV}$ in peak energy and photon flux of $10^{13}$ photon/s).

\subsection{Image Analysis for DXT}

Each diffraction spot was tracked by TrackPy (v0.3.2 https:/ / doi.org/10.5281/zenodo. 60550 (accessed on 1 May 2021) after correcting the background. Trajectories were analyzed using a custom software written within IGOR Pro (Wavemetrics, Lake Oswego). Data were recorded with $100 \mu \mathrm{s}$ per frame and a total measurement time was $10 \mathrm{~ms}$. The number of short-lived data (lifetime $\leq 0.4 \mathrm{~ms}$ ) were 2.5 times higher than that of the long-lived data $(0.5 \leq$ lifetime $\leq 10 \mathrm{~ms})$. Therefore the short-lived data were excluded from the analysis for minimizing noise.

Protein dynamics were analyzed using a temporal mean squared displacement (MSD) algorithm to extract the local behavior of the protein as a function of time. The MSD curves were fitted by the following function: $\delta^{2}(t)=D_{\alpha} t^{\alpha}+2 \beta^{2}$. $D_{\alpha}$ is the anomalous diffusion constant, a nonlinear relationship to time. $\alpha$ represents subdiffusion $(1>\alpha>0)$ or superdiffusion $(\alpha>1)$, and $\beta$ is a measurement error.

\subsection{Immunocytochemistry}

The transfected HEK293F cells were cultured for $48 \mathrm{hr}$ on poly-L-lysine coated 24 well plate at a density of $2 \times 10^{4}$ cells per well. Cells transfected with pcDNA3.1 were negative control (mock transfection). The cells were fixed with $4 \%$ paraformaldehyde for $30 \mathrm{~min}$, and then permeabilized with $0.05 \%$ Triton X-100 in PBS for $10 \mathrm{~min}$. Nonspecific antibody binding was blocked by incubating cells with 1\% BSA containing PBS for $30 \mathrm{~min}$. 
Cells were labeled with anti-FLAG M2 antibody $(1 \mu \mathrm{g} / \mathrm{mL})$ for $1 \mathrm{~h}$, followed by Alexa 555-conjugated secondary antibody (Invitrogen: A31622, $1 \mu \mathrm{g} / \mathrm{mL}$ ) for $1 \mathrm{~h}$. Nuclei were stained with DAPI (4',6-diamidino-2-phenylindole). Cells were examined using an ZEISS Axio Scope.A1 microscope. Pictures were collected by an AxioCam CCD camera (ZEISS) and AxioVision 4.8 software (ZEISS).

\subsection{Live-Cell Immunofluorescence Assay}

All the following steps were performed on ice. The cells in suspension were washed with PBS, precipitated by centrifugation and resuspended in $1 \mathrm{~mL}$ PBS containing $0.5 \%$ $\mathrm{BSA}$ and $1 \mu \mathrm{g} / \mathrm{mL}$ FLAG M2 antibody. After $1 \mathrm{~h}$, cells were washed by centrifugation twice in PBS. They were resuspended in $1 \mathrm{~mL}$ PBS containing $0.5 \%$ BSA and $1 \mu \mathrm{g} / \mathrm{mL}$ Alexa488-conjugated IgG (Thermofisher: A11001). After $30 \mathrm{~min}$, the cells were washed by centrifugation twice with PBS. The cells were resuspended in $1 \mathrm{~mL}$ PBS and dispensed into 96-well plate at a density of $1 \times 10^{5}$ cells per well. Fluorescence signals were measured at Ex/Em 495/519 nm using Flexstation 3 system. Background signals obtained from measurement of nontreated cells were subtracted from all data. Data are presented as mean values \pm standard deviation (SD) from four different experiments. Two-tailed paired Student $t$-test $p$-values indicate statistical significance $\left({ }^{*} p<0.05\right.$ and $\left.{ }^{* *} p<0.01\right)$.

\subsection{Calcium Influx Assay}

Calcium assay was performed using the FlexStation 3 system with the FLIPR Calcium 6 reagent (Molecular Devices Inc., San Jose, CA, USA). Ketanserin was applied to cells at a final concentration of $10^{-5}$ to $10^{-12} \mathrm{M}$ at $10 \mathrm{~min}$ prior to measurement. Alphamethylserotonin was applied at $10 \mu \mathrm{M}$ using the Flex mode. Four parameter logistic curves were generated. Data are presented as mean values $\pm \mathrm{SD}$ from five different experiments. The concentration at IC50 was analyzed by the Student $t$-test $\left({ }^{* *} p<0.01\right)$.

Supplementary Materials: The following are available online at https://www.mdpi.com/article/ 10.3390/ijms22105285/s1, Figure S1: Expression and function of 5- $\mathrm{HT}_{2 \mathrm{~A}} \mathrm{R}$ used in this experiment, Figure S2: Three Gaussian curve fitting of distribution of angular displacement for wild type $5-\mathrm{HT}_{2 \mathrm{~A}} \mathrm{R}$, Figure S3: Three Gaussian curve fitting of distribution of angular displacement for DRY / AAY mutant 5- $\mathrm{HT}_{2 \mathrm{~A}} \mathrm{R}$, Table S1: Parameters of MSD curves for wild type 5- $\mathrm{HT}_{2 \mathrm{~A}} \mathrm{R}$, Table S2: Parameters for single Gaussian fitting.

Author Contributions: Conceptualization, K.M., T.K. and Y.C.S.; methodology, K.M., T.K. and Y.C.S.; validation, K.M. and Y.C.S.; formal analysis, S.F., M.I., M.K. and H.S.; investigation, K.M., S.F., M.I., M.K., H.S., and Y.C.S.; resources, K.M. and Y.C.S.; data curation, S.F., M.I. and M.K.; writingoriginal draft preparation, K.M. and S.F.; writing - review and editing, M.K., H.S., T.K. and Y.C.S.; visualization, K.M. and S.F.; supervision, K.M. and Y.C.S.; project administration, K.M. and Y.C.S.; funding acquisition, K.M. and Y.C.S. All authors have read and agreed to the published version of the manuscript.

Funding: This work was supported by JSPS KAKENHI Grant Numbers JP17H05539, JP26102748, JP23591263 and by JST CREST Grant Number JP18071859, Japan.

Data Availability Statement: The data that support the findings of this study are available from the corresponding author upon reasonable request.

Acknowledgments: DXT experiments were performed with the approval of the Japan Synchrotron Radiation Research Institute (Proposal Nos 2019A1498, and 2019B1294), and of the Photon Factory Program Advisory Committee (Proposal No. 2017G556).

Conflicts of Interest: The authors declare no conflict of interest.

\section{References}

1. Hoyer, D.; Clarke, D.E.; Fozard, J.R.; Hartig, P.R.; Martin, G.R.; Mylecharane, E.J.; Saxena, P.R.; Humphrey, P.P. International Union of Pharmacology classification of receptors for 5-hydroxytryptamine (Serotonin). Pharmacol. Rev. 1994, 46, 157-203.

2. Nichols, D.E.; Nichols, C.D. Serotonin receptors. Chem. Rev. 2008, 108, 1614-1641. [CrossRef] 
3. McCorvy, J.D.; Roth, B.L. Structure and function of serotonin G protein-coupled receptors. Pharmacol. Ther. 2015, 150, 129-142. [CrossRef]

4. Garnovskaya, M.N.; Nebigil, C.G.; Arthur, J.M.; Spurney, R.F.; Raymond, J.R. 5-Hydroxytryptamine2A receptors expressed in rat renal mesangial cells inhibit cyclic AMP accumulation. Mol. Pharmacol. 1995, 48, 230-237. [PubMed]

5. Kimura, K.T.; Asada, H.; Inoue, A.; Kadji, F.M.N.; Im, D.; Mori, C.; Arakawa, T.; Hirata, K.; Nomura, Y.; Nomura, N.; et al. Structures of the 5-HT2A receptor in complex with the antipsychotics risperidone and zotepine. Nat. Struct. Mol. Biol. 2019, 26, 121-128. [CrossRef] [PubMed]

6. Kim, K.; Che, T.; Panova, O.; DiBerto, J.F.; Lyu, J.; Krumm, B.E.; Wacker, D.; Robertson, M.J.; Seven, A.B.; Nichols, D.E.; et al. Structure of a Hallucinogen-Activated Gq-Coupled 5-HT2A Serotonin Receptor. Cell 2020, 182, 1574-1588. [CrossRef] [PubMed]

7. Sasaki, Y.C.; Suzuki, Y.; Yagi, N.; Adachi, S.; Ishibashi, M.; Suda, H.; Toyota, K.; Yanagihara, M. Tracking of individual nanocrystals using diffracted $x$ rays. Phys. Rev. E 2000, 62, 3843-3847. [CrossRef]

8. Sasaki, Y.C.; Okumura, Y.; Adachi, S.; Suda, H.; Taniguchi, Y.; Yagi, N. Picometer-Scale Dynamical X-Ray Imaging of Single DNA Molecules. Phys. Rev. Lett. 2001, 87, 248102. [CrossRef]

9. Sekiguchi, H.; Suzuki, Y.; Nishino, Y.; Kobayashi, S.; Shimoyama, Y.; Cai, W.; Nagata, K.; Okada, M.; Ichiyanagi, K.; Ohta, N.; et al Real Time Ligand-Induced Motion Mappings of AChBP and nAChR Using X-ray Single Molecule Tracking. Sci. Rep. 2014, 4, 6384. [CrossRef]

10. Fujimura, S.; Mio, K.; Kuramochi, M.; Sekiguchi, H.; Ikezaki, K.; Mio, M.; Hengphasatporn, K.; Shigeta, Y.; Kubo, T.; Sasaki, Y.C. Agonist and Antagonist-Diverted Twisting Motions of a Single TRPV1 Channel. J. Phys. Chem. B 2020, 124, 11617-11624. [CrossRef]

11. Sekiguchi, H.; Kuramochi, M.; Ikezaki, K.; Okamura, Y.; Yoshimura, K.; Matsubara, K.; Chang, J.-W.; Ohta, N.; Kubo, T.; Mio, K.; et al. Diffracted X-ray Blinking Tracks Single Protein Motions. Sci. Rep. 2018, 8, 1-8. [CrossRef] [PubMed]

12. Kuramochi, M.; Omata, H.; Ishihara, M.; Hanslin, S.Ø.; Mizumaki, M.; Kawamura, N.; Osawa, H.; Suzuki, M.; Mio, K.; Sekiguchi, H.; et al. Tilting and rotational motions of silver halide crystal with diffracted X-ray blinking. Sci. Rep. 2021, 11, 1-9. [CrossRef]

13. Mio, K.; Ishihara, M.; Fujimura, S.; Sasaki, D.; Nozawa, S.; Ichiyanagi, K.; Fukaya, R.; Adachi, S.-I.; Kuramochi, M.; Sekiguchi, H.; et al. X-ray-based living-cell motion analysis of individual serotonin receptors. Biochem. Biophys. Res. Commun. 2020, 529, 306-313. [CrossRef] [PubMed]

14. Kepten, E.; Bronshtein, I.; Garini, Y. Improved estimation of anomalous diffusion exponents in single-particle tracking experiments. Phys. Rev. E 2013, 87, 052713. [CrossRef] [PubMed]

15. Hilger, D.; Masureel, M.; Kobilka, B.K. Structure and dynamics of GPCR signaling complexes. Nat. Struct. Mol. Biol. 2018, 25, 4-12. [CrossRef]

16. Rovati, G.E.; Capra, V.; Neubig, R.R. The Highly Conserved DRY Motif of Class A G Protein-Coupled Receptors: Beyond the Ground State. Mol. Pharmacol. 2006, 71, 959-964. [CrossRef]

17. Shapiro, D.A.; Kristiansen, K.; Weiner, D.M.; Kroeze, W.K.; Roth, B.L. Evidence for a Model of Agonist-induced Activation of 5-Hydroxytryptamine 2A Serotonin Receptors That Involves the Disruption of a Strong Ionic Interaction between Helices 3 and 6. J. Biol. Chem. 2002, 277, 11441-11449. [CrossRef]

18. Coleman, J.L.; Ngo, T.; Smith, N.J. The G protein-coupled receptor N-terminus and receptor signalling: N-tering a new era. Cell. Signal. 2017, 33, 1-9. [CrossRef]

19. Belmer, A.; Doly, S.; Setola, V.; Banas, S.M.; Moutkine, I.; Boutourlinsky, K.; Kenakin, T.; Maroteaux, L. Role of the N-terminal region in G protein-coupled receptor functions: Negative modulation revealed by 5-HT2B receptor polymorphisms. Mol. Pharmacol. 2014, 85, 127-138. [CrossRef]

20. Wacker, D.; Wang, S.; McCorvy, J.D.; Betz, R.M.; Venkatakrishnan, A.; Levit, A.; Lansu, K.; Schools, Z.L.; Che, T.; Nichols, D.E.; et al. Crystal Structure of an LSD-Bound Human Serotonin Receptor. Cell 2017, 168, 377-389.e12. [CrossRef]

21. Kanagarajadurai, K.; Malini, M.; Bhattacharya, A.; Panicker, M.M.; Sowdhamini, R. Molecular modeling and docking studies of human 5-hydroxytryptamine 2A (5-HT2A) receptor for the identification of hotspots for ligand binding. Mol. BioSyst. 2009, 5, 1877-1888. [CrossRef] [PubMed]

22. Denzinger, K.; Nguyen, T.N.; Noonan, T.; Wolber, G.; Bermudez, M. Biased Ligands Differentially Shape the Conformation of the Extracellular Loop Region in 5-HT $2 \mathrm{~B}$ Receptors. Int. J. Mol. Sci. 2020, 21, 9728. [CrossRef]

23. Huang, S.K.; Pandey, A.; Tran, D.P.; Villanueva, N.L.; Kitao, A.; Sunahara, R.K.; Sljoka, A.; Prosser, R.S. Delineating the conformational landscape of the adenosine $A_{2 A}$ receptor during $G$ protein coupling. Cell 2021, 184, 1884-1894.e14. [CrossRef] [PubMed]

24. Gurevich, V.V.; Gurevich, E.V. Molecular mechanisms of GPCR signaling: A structural perspective. Int. J. Mol. Sci. 2017, 18, 2519. [CrossRef]

25. Ng, H.W.; Laughton, C.A.; Doughty, S.W. Molecular Dynamics Simulations of the Adenosine A2a Receptor in POPC and POPE Lipid Bilayers: Effects of Membrane on Protein Behavior. J. Chem. Inf. Model. 2014, 54, 573-581. [CrossRef] [PubMed] 